\title{
Influência da infestação de Diatraea saccharalis (Fabr.) sobre parâmetros tecnológicos da cana-de-açúcar
}

\author{
Leila Luci Dinardo-Miranda (*); Juliano Vilela Fracasso; Ivan Antonio dos Anjos; Julio Garcia; \\ Viviane Pereira da Costa
}

Instituto Agronômico, Centro de Cana-de-Açúcar, Rodovia SP 333, km 321, 14001-970 Ribeirão Preto (SP), Brasil.

(*) Autora correspondente: leiladinardo@iac.sp.gov.br

Recebido: 29/nov./2011; Aceito: 4/set./2012

\section{Resumo}

A broca Diatraea saccharalis é uma das pragas mais importantes da cana-de-açúcar no Brasil, razão pela qual é relevante quantificar a interferência de seu ataque nos parâmetros tecnológicos dos colmos, utilizados como matéria-prima na indústria de açúcar e etanol. Assim, o objetivo do presente trabalho foi avaliar os efeitos da intensidade de infestação sobre os parâmetros tecnológicos, entre os quais fibra na cana e pol na cana, das cultivares IAC91-1099, IACSP93-3046 e IACSP95-5000. Para tanto, os colmos coletados em campo foram agrupados de maneira a compor amostras com 0, 3, 6, 9, 12 e 15\% de entrenós brocados, que foram então analisadas. Maiores ataques de broca resultaram em aumento nos teores de fibra e de açúcares redutores, e redução nos teores de pol na cana e na pureza. Na média, a curva que representa a relação entre pol na cana (y) e intensidade de infestação ( $x$, \% de entrenós brocados) é dada por y=16,591-0,0672x, cujo coeficiente de determinação $\left(r^{2}\right)$ foi 0,92.

Palavras-chave: Saccharum, broca da cana, perdas.

\section{Influence of Diatraea saccharalis (Fabr.) infestation on technological parameters of sugarcane}

\begin{abstract}
Sugarcane borer Diatraea saccharalis is one of the most important pests of sugarcane in Brazil, being its influence on technological parameters of the new cultivars stalks used as raw material for sugar and ethanol industry unknown. The objective of this study was to evaluate the effect of infestation levels on technological parameters of the stalks of three sugarcane varieties IAC91-1099, IACSP93-3046 and IACSP95-5000. Stalks harvested in field were grouped in order to compose samples with $0,3,6,9,12$ and 15\% of bored internodes. High levels of bored internodes resulted in high values of fiber and reducing sugars and in lower values of sugarcane pol and purity. On average, the curve that represent the relationship between sugarcane pol $(y)$ and infestation level $(x)$ was $y=16.591-0.0672 x$, with the coefficient of determination $\left(r^{2}\right)$ of 0.92 .
\end{abstract}

Key words: Saccharum, sugarcane borer, loses.

\section{INTRODUÇÃO}

A broca Diatraea saccharalis Fabr. (Lepidoptera: Crambidae) é uma das mais importantes pragas da cana-de-açúcar no Brasil, e está amplamente distribuída em todas as regióes canavieiras do país (DinARDoMiranda, 2008). O dano é causado pelas lagartas que abrem galerias no interior dos colmos, provocando morte de grande número de perfilhos em canaviais jovens e acentuada redução de produtividade em canaviais mais desenvolvidos, pois os colmos atacados perdem massa, são menores e mais finos e muitos secam e morrem (Téran et al., 1985; Botelho e Macedo, 2002).

Em condiçôes favoráveis, através dos orifícios feitos pelas lagartas entram pragas secundárias, como Metamasius hemipterus (L.) (Coleoptera: Curculioniodae), que acentuam as perdas no campo. Também é comum a entrada de diversos micro-organismos, especialmente fungos, que causam a "podridão vermelha", com redução do teor de açúcar nos colmos devido à inversão da sacarose armazenada na planta e sua transformaçáo em glicose e frutose. $\mathrm{Na}$ indústria, os micro-organismos presentes no colmo contaminam o caldo, prejudicando os processos industriais, por dificultar a obtenção de açúcar de qualidade e inibir a fermentação (BotelHo e MACEdo, 2002; Stupiello, 2005).

Assim, a associação da broca com micro-organismos presentes no campo resulta no complexo broca-podridão, responsável por significativas perdas agroindustriais. Tais perdas foram objeto de estudo de VALSECHI et al. (1976), que trabalharam com a cultivar CB41-76 e concluíram que o açúcar nos colmos ( $\mathrm{y}$, açúcar provável \% colmo) estava diretamente ligado à infestaçáo do complexo broca-podridão (x, \% de entrenós infectados pelo complexo broca-podridão), de acordo com a fórmula $y=14,8272-0,0563 x$. 
Embora a redução na qualidade da cana-de-açúcar como matéria-prima na indústria seja causada pelo complexo broca-podridão, ou seja, pela broca e pelos micro-organismos que entram no colmo através dos furos abertos, o índice mais utilizado para expressar o dano é a intensidade de infestação, representado pela porcentagem de entrenós brocados (Metcalfe, 1969).

Em trabalhos desenvolvidos na Copersucar no fim da década de 1980 , determinou-se que, a cada $1 \%$ de entrenós brocados por $D$. saccharalis, haveria reduçôes médias de $0,77 \%$ na produtividade de colmos, $0,25 \%$ na produtividade de açúcar e $0,20 \%$ na produtividade de etanol (TÉran et al., 1986; Precetti et al., 1988). Foram observadas ainda significativas diferenças entre as cultivares estudadas quanto às perdas, estando ao redor de $0,24 \%$ de redução na PCC (pol na cana, pol \% cana, porcentagem aparente de sacarose na cana) para cada $1 \%$ de entrenós brocados na cultivar SP71-1143 e de $0,10 \%$ de redução na PCC para cada $1 \%$ de entrenós brocados na cultivar SP70-1084 (Precetti et al., 1988).

Dados mais recentes de trabalhos realizados na Copersucar e apresentados por ARRIgONI (2002), envolvendo algumas cultivares plantadas no fim da década de 1990 , revelaram que as perdas, a cada $1 \%$ de entrenós brocados por $D$. saccharalis, poderiam chegar a $1,50 \%$ na produtividade de colmos, $0,49 \%$ na produtividade de açúcar e $0,28 \%$ na produtividade de etanol. Esse autor também relatou diferenças significativas entre as cultivares estudadas.

Comparando os trabalhos desenvolvidos na Copersucar anteriormente citados, verifica-se aparente aumento de suscetibilidade das cultivares mais modernas, pois, sob mesma infestação, sofreriam perdas mais acentuadas de açúcar. Visto que novas cultivares são constantemente liberadas para plantio comercial, o objetivo deste trabalho foi avaliar os efeitos da intensidade de infestação de $D$. sacharalis sobre os parâmetros tecnológicos de novos genótipos.

\section{MATERIAL E MÉTODOS}

O ensaio foi desenvolvido em Ribeirão Preto (SP), utilizando as cultivares IACSP95-5000 (cana-planta e cana-soca, com respectivamente 14 e 10 meses de idade), IACSP93-3046 (cana-planta com 14 meses de idade) e IAC91-1099 (cana-planta com 15 meses de idade).

De cada cultivar em campo, foram coletados cerca de 500 colmos em junho de 2010. Após a coleta, estes colmos foram levados ao laboratório de análise tecnológica, onde cada um foi aberto longitudinalmente para permitir a visualização dos entrenós brocados. Após contagem do total de entrenós e dos entrenós brocados em cada colmo, foram montados feixes com 10 colmos, agrupados de maneira a resultar em intensidades de infestaçâo de $0,3,6,9$, 12 e $15 \%$ de entrenós brocados, que se constituíram nos tratamentos. Para cada cultivar, foram analisados cinco feixes de cada tratamento, compondo, portanto, cinco repetiçóes. Assim, o trabalho foi desenvolvido com tratamentos em esquema fatorial $3 \times 6$, sendo o primeiro fator representado pelas cultivares e o segundo pelas intensidades de infestação, e cinco repetiçôes, em delineamento inteiramente casualizado.

Os colmos foram analisados no laboratório de análise tecnológica do Centro de Cana do IAC, de acordo com a metodologia para Pagamento de Cana pelo Teor de Sacarose, PCTS, descrita por Fernandes (2001). Entre outros parâmetros, foram obtidos os teores de fibra (fibra \% cana, porcentagem de matéria insolúvel em água presente na cana), PCC (pol \% cana, porcentagem aparente de sacarose na cana), pureza (pureza \% cana, porcentagem de sacarose contida nos sólidos solúveis) e açúcares redutores na cana (ARC \% cana, porcentagem de açúcares que reduzem o cobre, do estágio cúprico para cuproso, na cana).

Os dados foram submetidos à análise de variância pelo teste $\mathrm{F}$ e, em seguida, as médias foram comparadas pelo teste de Tukey a 5\% de significância.

\section{RESULTADOS E DISCUSSÃO}

Os teores de fibra (fibra \% cana), PCC (pol \% cana), pureza (pureza \% cana) e açúcares redutores na cana (ARC \% cana) estáo nas tabelas 1 a 4 . Para a cultivar IACSP95-5000, estão apresentados os dados médios, obtidos em cana-planta e cana-soca (Tabela 1 ).

Não foram observadas diferenças significativas em relação aos teores de fibra em colmos com diferentes intensidades de infestação, em nenhuma das cultivares estudadas (Tabelas 1 a 3), nem mesmo com a análise conjunta dos dados (Tabela 4). Este resultado é diferente do constatado nos trabalhos de Valsechi et al. (1976) e Preceetti et al. (1988), nos quais o ataque de broca resultou em aumento nos teores de fibra. Naqueles estudos, porém, os autores trabalharam com índices de intensidade de infestação mais elevados (de até 50\%), o que provavelmente explicam as diferenças obtidas.

Tabela 1. Valores de fibra (fibra \% cana), PCC (pol \% cana), pureza (pureza \% cana) e açúcares redutores (ARC, açúcares redutores \% cana) obtidos em função da intensidade de infestação (II, \% de entrenós brocados) de D. saccharalis em colmos da IACSP95-5000 (cana planta e soca)

\begin{tabular}{lcccccccc}
$\begin{array}{l}\text { II } \\
\text { (\% de entrenós } \\
\text { brocados) }\end{array}$ & Fibra & PCC & Pureza & ARC \\
\hline 0 & 11,43 & a & 15,70 & a & 89,67 & a & 0,48 & a \\
\hline 3 & 11,47 & a & 15,67 & ab & 90,00 & a & 0,47 & a \\
\hline 6 & 11,25 & a & 15,21 & ab & 89,33 & a & 0,50 & a \\
\hline 9 & 11,39 & a & 15,07 & ab & 88,87 & a & 0,51 & a \\
\hline 12 & 11,51 & a & 15,07 & ab & 88,70 & a & 0,51 & a \\
\hline 15 & 11,44 & a & 14,93 & b & 88,27 & a & 0,52 & a
\end{tabular}

Médias na mesma coluna seguidas por letras iguais nấo diferem entre si pelo teste de Tukey a $5 \%$ de probabilidade. 
As diferenças entre os tratamentos quanto aos valores de PCC foram significativas para todas as cultivares estudadas, e o aumento da intensidade de infestação resultou em queda dos valores de PCC (Tabelas 1 a 4). Na média, quando a intensidade de infestação foi igual ou superior a $9 \%$ de entrenós brocados, a PCC diferiu da testemunha, não infestada. Quedas nos valores de PCC associadas ao aumento na intensidade de infestação também foram observadas por VAlseChi et al. (1976) e Precetti et al. (1988) e ilustram os danos provocados pelo ataque de broca.

Para a cultivar IACSP95-5000, a relação entre o PCC (y) e a intensidade de infestação (x) é dada pela curva $y=15,689-0,0551 x$, cujo coeficiente de determinação $\left(\mathrm{r}^{2}\right)$ foi 0,88 , significando que a intensidade de infestação, neste caso, explica $88 \%$ da variabilidade existente nos valores de PCC. Foram determinados F=29, 45 e p=0,006, indicando que a curva é significativa a $1 \%$.

Para IACSP93-3046, a curva $y=17,716-0,0794 x$ $\left(r^{2}=0,96\right)$ é a que melhor descreve a relação entre PCC e intensidade de infestaçáo ( $F=92,54 ; p=0,0007)$, enquanto para a IAC91-1099, é a curva $y=17,293-0,0807 x$ $\left(\mathrm{r}^{2}=0,70 ; \mathrm{F}=8,93 ; \mathrm{p}=0,04\right)$. Na média, a curva que representa a relação entre PCC e intensidade de infestação é $y=16,591-0,0672\left(r^{2}=0,92 ; F=45,73 ; p=0,002\right)$, ilustrada na figura 1 . Considerando as curvas obtidas, verifica-se que cada $1 \%$ de entrenós brocados reduziu a PCC em $0,35 \%, 0,45 \%$ e $0,47 \%$, nas cultivares IACSP95-5000,

Tabela 2. Valores de fibra (fibra \% cana), PCC (pol \% cana), pureza (pureza \% cana) e açúcares redutores (ARC, açúcares redutores \% cana) obtidos em função da intensidade de infestação (II, \% de entrenós brocados) de D. saccharalis em colmos da IACSP93-3046

\begin{tabular}{|lclll|}
$\begin{array}{l}\text { II } \\
\text { (\% de entrenós brocados) }\end{array}$ & Fibra & \multicolumn{1}{c}{ PCC } & Pureza & ARC \\
\hline 0 & $12,52 \mathrm{a}$ & $17,66 \mathrm{a}$ & $93,03 \mathrm{ab}$ & $0,38 \mathrm{ab}$ \\
\hline 3 & $12,60 \mathrm{a}$ & $17,62 \mathrm{a}$ & $93,44 \mathrm{a}$ & $0,36 \mathrm{a}$ \\
\hline 6 & $12,69 \mathrm{a}$ & $17,23 \mathrm{ab}$ & $93,11 \mathrm{ab}$ & $0,37 \mathrm{ab}$ \\
\hline 9 & $12,93 \mathrm{a}$ & $16,88 \mathrm{ab}$ & $92,20 \mathrm{ab}$ & $0,40 \mathrm{ab}$ \\
\hline 12 & $12,84 \mathrm{a}$ & $16,74 \mathrm{~b}$ & $91,74 \mathrm{~b}$ & $0,41 \mathrm{~b}$ \\
\hline 15 & $13,15 \mathrm{a}$ & $16,59 \mathrm{~b}$ & $92,12 \mathrm{ab}$ & $0,40 \mathrm{~b}$ \\
\hline
\end{tabular}

Médias na mesma coluna seguidas por letras iguais năo diferem entre si pelo teste de Tukey a $5 \%$ de probabilidade.

Tabela 3. Valores de fibra (fibra \% cana), PCC (pol \% cana), pureza (pureza \% cana) e açúcares redutores (ARC, açúcares redutores \% cana) obtidos em função da intensidade de infestação (II, \% de entrenós brocados) de D. saccharalis em colmos da IAC91-1099

\begin{tabular}{lcccc}
$\begin{array}{l}\text { II } \\
\text { (\% de entrenós brocados) }\end{array}$ & Fibra & PCC & Pureza & ARC \\
\hline 0 & $11,64 a$ & $16,95 a$ & $93,36 a$ & $0,37 a$ \\
\hline 3 & $12,13 a$ & $17,35 a$ & $93,52 a$ & $0,37 a$ \\
\hline 6 & $11,88 a$ & $16,82 a$ & $92,86 a b$ & $0,39 a b$ \\
\hline 9 & $11,90 a$ & $16,65 a$ & $92,89 a b$ & $0,39 a b$ \\
12 & $11,95 a$ & $16,65 a$ & $91,87 a b$ & $0,42 a b$ \\
15 & 11,82 a & 15,71 b & $90,01 b$ & $0,47 b$ \\
\hline
\end{tabular}

Médias na mesma coluna seguidas por letras iguais năo diferem entre si pelo teste de Tukey a $5 \%$ de probabilidade.
IACSP93-3046 e IAC91-1099 respectivamente. Na média, a cada $1 \%$ de entrenós brocados, a redução na PCC foi de $0,41 \%$.

Considerando que Precetti et al. (1988) determinaram que as cultivares plantadas no fim da década de 1980 perdiam $0,19 \%$ da PCC a cada $1 \%$ de entrenós brocados e que esta redução, neste trabalho foi de $0,41 \%$ em média, pode-se inferir que as cultivares mais modernas são mais suscetíveis à broca do que as antigas, pois ocorrem maiores perdas em função do seu ataque.

A mesma observação pode ser feita ao comparar os dados de Arrigoni (2002) com os de Téran et al. (1986), pois enquanto estes últimos registraram que a cada $1 \% \mathrm{de}$ entrenós brocados resultava em redução de $0,77 \%$ na produtividade de colmos, $0,25 \%$ na produtividade de açúcar e $0,20 \%$ na produtividade de álcool, Arrigoni (2002), trabalhando com cultivares mais modernas que as estudadas por TÉran et al. (1986), determinou que as perdas, a cada $1 \%$ de entrenós brocados poderiam chegar a 1,50\% na produtividade de colmos, $0,49 \%$ na produtividade de açúcar e 0,28\% na produtividade de álcool.

Para IACSP95-5000, não foram registradas diferenças significativas entre os tratamentos quanto à pureza e ARC (Tabela 1). Para as cultivares IACSP93-3046 e IAC91-1099, as diferenças entre os tratamentos quanto a esses dois parâmetros foram significativas (Tabelas 2 e 3), assim como o foram ao se considerar os dados médios das

Tabela 4. Valores de fibra (fibra \% cana), PCC (pol \% cana), pureza (pureza \% cana) e açúcares redutores (ARC, açúcares redutores \% cana) obtidos em função da intensidade de infestação (II, \% de entrenós brocados) de $D$. saccharalis (média das três cultivares)

\begin{tabular}{lllll}
$\begin{array}{l}\text { II } \\
\text { (\% de entrenós } \\
\text { brocados) }\end{array}$ & Fibra & PCC & Pureza & ARC \\
\hline 0 & $11,77 \mathrm{a}$ & $16,50 \mathrm{ab}$ & $91,43 \mathrm{ab}$ & $0,43 \mathrm{ab}$ \\
\hline 3 & $11,92 \mathrm{a}$ & $16,57 \mathrm{a}$ & $91,75 \mathrm{a}$ & $0,42 \mathrm{a}$ \\
\hline 6 & $11,77 \mathrm{a}$ & $16,11 \mathrm{bc}$ & $91,16 \mathrm{ab}$ & $0,44 \mathrm{ab}$ \\
\hline 9 & $11,90 \mathrm{a}$ & $15,92 \mathrm{~cd}$ & $90,70 \mathrm{abc}$ & $0,45 \mathrm{abc}$ \\
\hline 12 & $11,95 \mathrm{a}$ & $15,88 \mathrm{~cd}$ & $90,25 \mathrm{bc}$ & $0,46 \mathrm{bc}$ \\
\hline 15 & $11,96 \mathrm{a}$ & $15,54 \mathrm{~d}$ & $89,67 \mathrm{c}$ & $0,48 \mathrm{c}$ \\
\hline
\end{tabular}

Médias na mesma coluna seguidas por letras iguais náo diferem entre si pelo teste de Tukey a $5 \%$ de probabilidade.

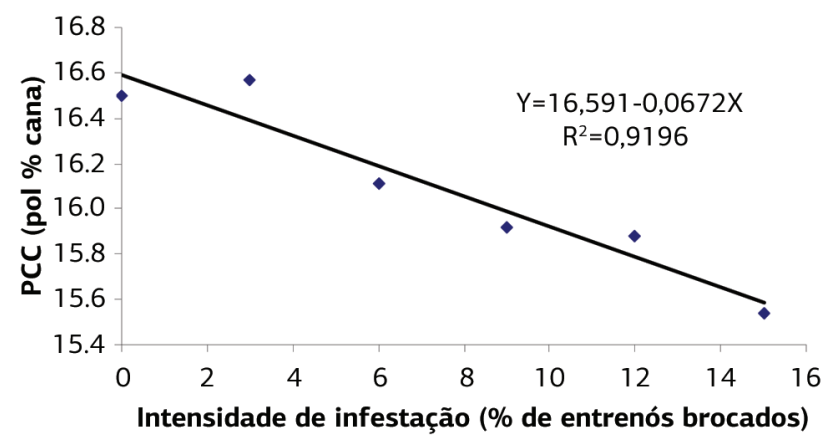

Figura 1. Relação entre PCC e a intensidade de infestação. Cada símbolo representa as médias das três cultivares. 
três cultivares (Tabela 4), revelando que a broca causou redução na porcentagem de sacarose da cana e aumento de açúcares redutores, em concordância com VALSECHI et al. (1976), Precetti et al. (1988).

\section{CONCLUSÃO}

Aumentos nos índices de infestação de broca resultam em diminuição na qualidade tecnológica da cana, devido ao aumento nos teores de açúcares redutores e à redução nos teores de pol na cana e pureza, nas cultivares IAC91-1099, IACSP93-3046 e IACSP95-5000.

\section{REFERÊNCIAS}

ARRIGONI, E.B. Broca da cana-de-açúcar: Importância econômica e situaçấo atual. In: ARRIGONI, E.B.; DINARDOMIRANDA, L.L.; ROSSETTO, R. Pragas da cana-de-açúcar Importância econômica e enfoques atuais. Piracicaba: STAB/IAC/ CTC, 2002 (Cd-rom).

BOTELHO, P.S.M.; MACEDO, N. Cotesia flavipes para o controle de Diatraea saccharalis. In: PARRA, J.R.P.; BOTELHO, P.S.M.; CORREA-FERREIRA, B.S.; BENTO, J.M.S. Controle biológico no Brasil: Parasitóides e predadores. São Paulo: Manole, 2002. p.409-425.

DINARDO-MIRANDA, L.L. Pragas. In: DINARDOMIRANDA, L.L.; VASCONCELOS, A.C.M.; LANDELL,
M.G.A. (Ed.). Cana-de-açúcar. Campinas: Instituto Agronômico, 2008. p.349-404.

FERNANDES, A.C. Cálculos na agroindústria da cana-de-açúcar. Piracicaba: Edição do autor, 2001. 215p.

METCALFE, J.R. The estimation of loss caused by sugar cane moth borer. In: WILLIAMS, J.R.; METCALFE, J.R.; MUNGOMERY, R.W.; MATHES, R. (Ed.). Pests of sugarcane. Amsterdan: Elsevier, 1969. p.61-79.

PRECETTI, A.A.C.M.; TERÁN, F.O.; SANCHEZ, A.G. Alteraçôes nas características tecnológicas de algumas variedades de cana-de-açúcar, devidas ao dano da broca Diatraea saccharalis. Boletim Técnico Copersucar, v. 40, p.3-8, 1988.

STUPIELLO, J.P. O complexo broca-podridão vermelha. STAB Açúcar, Álcool e Subprodutos, v.24, p.14, 2005.

TÉRAN, F.O.; PRECETTI, A.A.C.M.; SÁNCHEZ, A.G. Importância econômica, aspectos bioecológicos e manejo populacional da broca da cana-de-açúcar, Diatraea saccharalis. In: SEMINÁRIO DE TECNOLOGIA AGRONÔMICA, 3., 1986. Piracicaba. Anais... São Paulo: Copersucar, 1986. p.153-167.

TÉRAN, F.O.; SÁNCHEZ, A.G.; PRECETTI, A.A.C.M. Estudos sobre resistência da cana à broca em telado: Primeiros resultados. Boletim Técnico Copersucar, v.29, p.2-11. 1985.

VALSECHI, O.; OLIVEIRA, E.R.; BARBIN, D.; NOVAES, F.W. Estudos sobre alguns efeitos da broca (Diatraea saccharalis Fabr.) na cana-de-açúcar e seus reflexos na indústria açucareira. Piracicaba: ESALQ/Departamento de Tecnologia Rural, 1976. 140p. 